\title{
Laparoscopic Cecoplication for Mobile Cecum
}

A 51-year-old woman presented with a history of right lower abdominal discomfort and severe constipation, which had not responded to treatment with various cathartics and antiflatulents. A barium enema showed a dilated cecum, which moved when she changed position during the examination (Figure 1).
After she had given informed consent, laparoscopic cecoplication was carried out. Under general anesthesia, a pneumoperitoneum was established to $8 \mathrm{mmHg}$. Four trocars were placed as shown in Figure 2, and laparoscopic cecoplication was carried out with the patient in the Trendelenburg position and inclining to the left. 


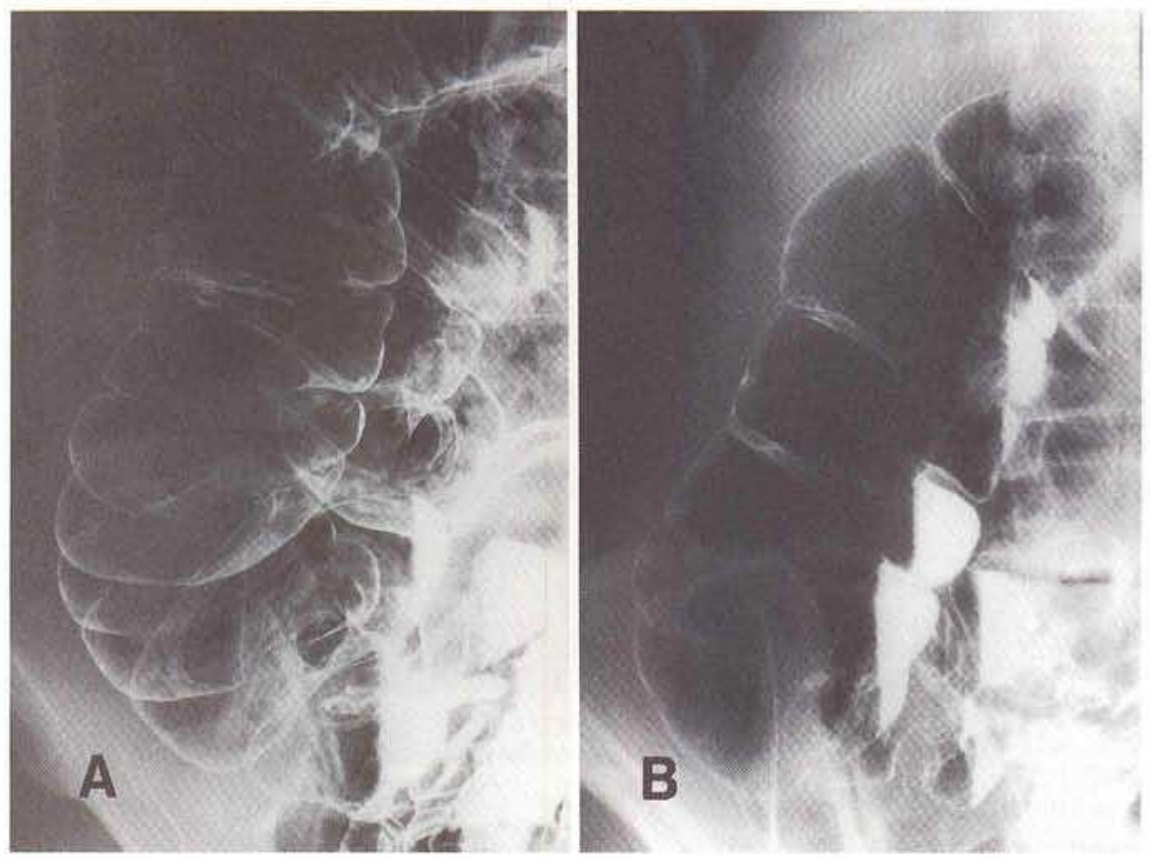

Figure $1 \mathrm{a}, \mathrm{b}$ : Dilated and mobile cecum.

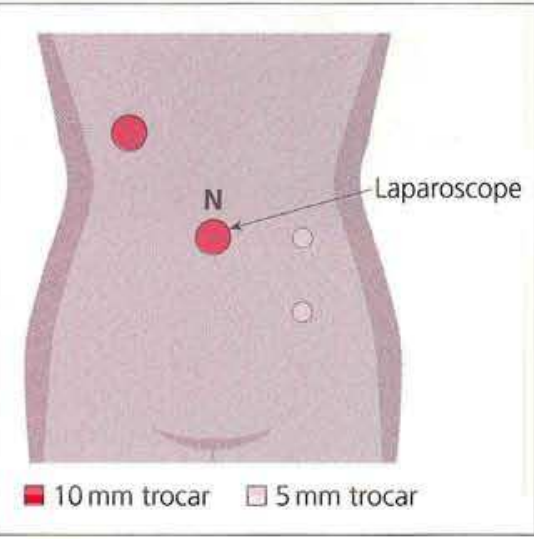

After an appendectomy using Endoloops, both taenias of the cecum and part of the ascending colon were sutured with six interrupted 3-0 nylon sutures, using the ten-Horn method (Figure 3). The total operating time was 145 minutes, and no complications were encountered. The patient had no postoperative pain, and oral nutrition was started on the second postoperative day. The defecation pattern returned to normal, and the abdominal discomfort disappeared.

The procedure was carried out safely and effectively. The advantages of the procedure were reduced postoperative pain, small surgical wounds, and provision of an adequate surgical field to carry out a search for any other abnormality that might be causing symptoms similar to those of mobile cecum $(1-3)$.

S. Kakizoe', K. Kakizoe', H. Kakizoe ${ }^{2}$, Y. Kakizoe', T. Kakizoe $^{2}$, S. Kakizoe!

'Dept. of Surgery

${ }^{2}$ Dept. of Medicine, Kakizoe Hospital, Nagasaki, Japan

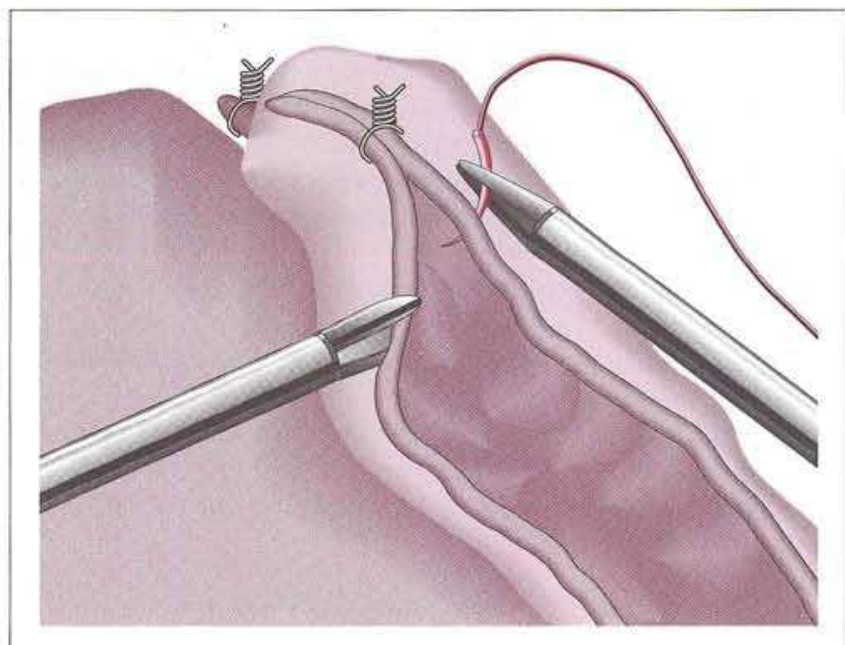

Figure 3: Laparoscopic cecoplication. Both taenias of the cecum and part of the ascending colon are sutured.

\section{References}

1. Nicole R. Das Coecum-mobile-Syndrom. Praxis 1967; 56: $869-72$.

2. Gupta S, Gupta SK. Acute caecal volvulus: report of 22 cases and review of literature. Ital J Gastroenterol 1993; 25: 380-4.

3. Barros F de C, Kunzle JR, Ribeiro Filho J do A. Apendicite aguda na gravidez. Rev Paul Med 1991; 109: 9-13.

Corresponding Author

S. Kakizoe, M.D., Dept. of Surgery

Kakizoe Hospital, Kagamigawa 278, Hirado

Nagasaki 859-51, Japan

Fax: + 81-950-22-5131 